\title{
Stress fractures of the hip in Royal Marine recruits under training: a retrospective analysis
}

\author{
M. D. Stoneham MA, MB BChir, RN and N. V. Morgan MB BS, FRCSEd, RN \\ Commando Training Centre, Royal Marines, Lympstone, Exmouth, UK
}

\begin{abstract}
At the Commando Training Centre, Royal Marines (CTCRM), a retrospective analysis of the occurrence of one form of stress fracture - that of the hip - has shown that this fracture is a significant cause of morbidity in the recruits. Most fractures presented in the last few weeks of training, which may reflect the increasing workload that the training involves. Two different fracture sites are identified, but there is no discernible difference in presentation or outcome between them. The condition may be easily misdiagnosed as a more trivial injury. A careful history and examination, and a low threshold for radiographic and scintigraphic investigation are important for diagnosis, and to avoid the catastrophic failure of the fracture seen in one of our patients.
\end{abstract}

Keywords: Stress fracture, femoral, scintigraphy, radiographs

Stress fractures are well recognized complications of training, occurring in both competitive athletes and in soldiers under military training. The first stress fractures were described by Breithaupt in $1855^{1}$, occurring in Prussian military recruits. The first radiograph of a stress fracture, a 'march' fracture of a metatarsal, was published by Stechow in $1897^{2}$. Since that time, there has been an extensive literature on the occurrence, incidence, aetiology and treatment of all forms of stress fractures.

Stress fractures of the femur are among the least common of all stress fractures in most series ${ }^{3}$, varying from $0.6 \%$ of stress fractures in one series of 179 military recruits ${ }^{4}$ to $10 \%$ in a series of athleticsinduced stress fractures ${ }^{5}$. However, one prospective study of 295 Israeli military recruits ${ }^{6}$ showed a high incidence of stress fractures of $31 \%$ over a 14 -week period, and of these, $33.6 \%$ were femoral - including fractures of medial femoral condyle, distal femur, proximal femur and femoral neck. However, this study differed from the others in that it was prospective.

Address for correspondence: Mr T. Paes, Consultant Surgeon, Hillingdon Hospital, Hillingdon, Middlesex UB8 3NN, UK (C) 1991 Butterworth-Heinemann Ltd.

0306-3674/91/030145-04
Most recent studies on stress fractures have concluded that the incidences of the various fractures is increasing, but that this is probably due to improved and earlier diagnostic intervention.

We have looked at the incidence of one group of stress fractures - of the upper femur - occurring at the Commando Training Centre, Royal Marines (CTCRM) between October 1989 and January 1991. An attempt is made to see whether there were any identifiable common factors in the history, examination or investigation of these injuries.

\section{Materials and methods}

All patients reported in this study were Royal Marine recruits under training at CTCRM between October 1989 and January 1991 (approximately 1400). Groups of Royal Marine recruits in training undergo a 30 -week training programme at CTCRM. The physical programme is extremely arduous, and increases progressively over the 30 weeks, culminating in the 2-week commando course during weeks 27 and 28. Recruits are preselected by assessment courses as being suitable for training, and are medically examined on entry, including careful enquiry about previous sports injury. Recruits are aged between 16 and 27 years of age. Any recruit who develops a serious medical problem is withdrawn from training and enters a remedial organization called Hunter Troop. Within Hunter Troop, there is the facility to place patients on bed-rest in the sick-bay. There is access to physiotherapy, to remedial instructors, and to progressively increasing levels of activity as the recruit recovers from the injury.

Patients included in the present retrospective study have been selected on the basis of clinical, radiographic and scintigraphic findings. Recruits who presented with persistent, unremitting hip or thigh pain were seen by a medical officer for further assessment. In patients with no known history of trauma, symptoms such as night pain, heel-strike pain or persistent limp raised the clinical index of suspicion of stress fracture. Restriction of movements of the hip and anterior tenderness over the hip joint or upper femur was also considered a serious sign of injury. Radiographs were performed in the sick-bay on all patients when the first suspicion of stress 
fracture was entertained. Technetium-99m ( $\left.{ }^{99 m} \mathrm{Tc}\right)$ bone scans were performed on all patients unless there was obvious radiographic evidence of fracture.

Patients with a proven diagnosis of stress fracture of the hip were admitted to the sick-bay at CTCRM for a period of bed-rest. Regular simple analgesia such as paracetamol $500 \mathrm{mg}$ q.d.s. and night sedation (temazepam $20 \mathrm{mg}$ ) was administered, if necessary, whilst patients were on the ward. When patients were able to walk freely without pain they were discharged from the ward for remedial physiotherapy, and started remedial training in Hunter Troop. A gradual and progressive increase in daily exercise whilst in Hunter Troop was undertaken, under the supervision of the remedial gymnasts. When the recruits were deemed to be fully fit, they were returned to training. Repeat bone scans were not performed.

Retrospective analysis was performed of the week of training of the recruit, the site of stress fracture sustained, time of first presentation, delay between first presentation and diagnosis, and outcome after treatment.

\section{Results}

Ten recruits were diagnosed as having stress fractures of the hip or upper femur during this period. The details of the individual cases are shown in Table 1.

There are two different types of stress fracture reported here: fracture of the femoral neck (Figure 1), and fracture of the femoral shaft (Figure 2). There appears to be no difference in the mode of presentation of the two fractures.

Seventy per cent of these stress fractures occurred in the last 8 weeks of training when the loads carried by the recruits and the distances travelled in training marches were steadily increased (Figure 3).

\section{Discussion}

Our retrospective study of stress fractures of the hip has shown a surprising number of such fractures in a relatively short time. Previous studies have not

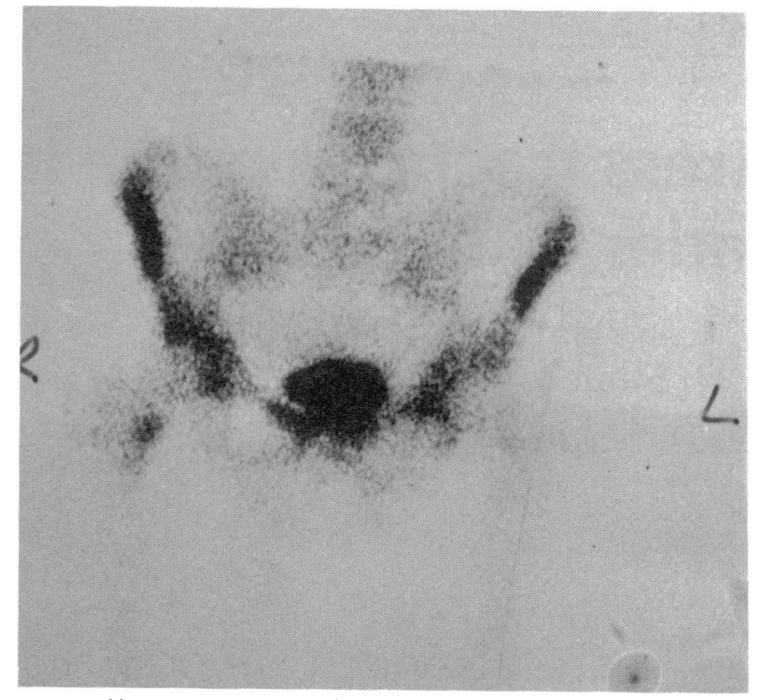

Figure 1. ${ }^{99 m} \mathrm{Tc}$-scintigram showing increased uptake in neck of right femur (left)

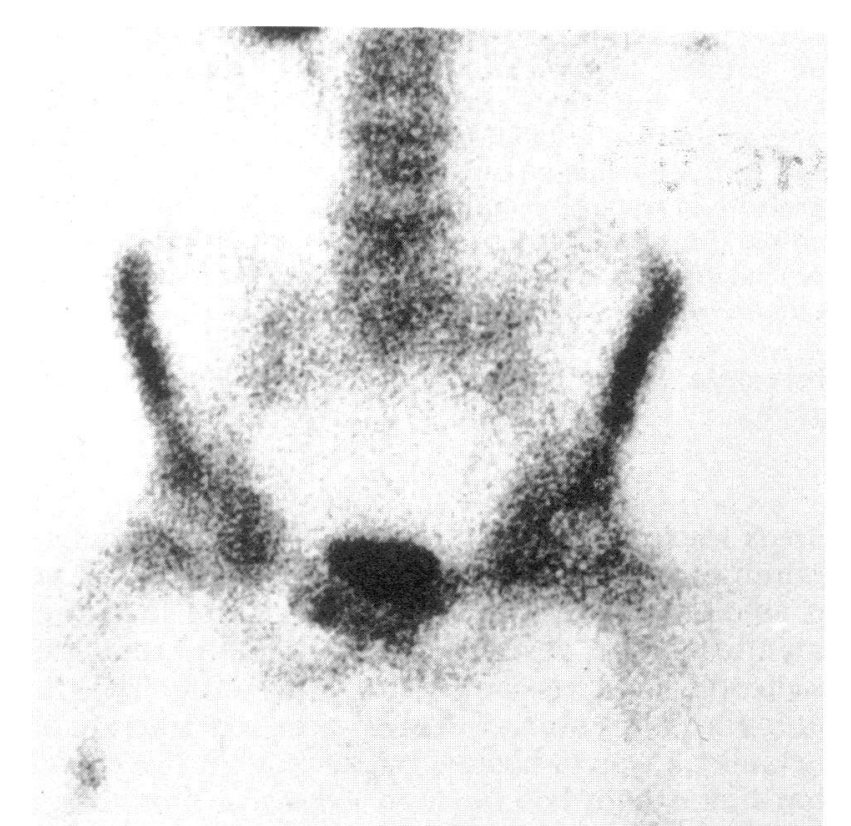

Figure $2 .{ }^{99 m}$ Tc-scintigram showing increased uptake in the femoral shaft of the right leg (left)

Table 1. Stress fractures of the hip

\begin{tabular}{|c|c|c|c|c|c|c|c|c|c|}
\hline Case & $\begin{array}{c}\text { Age } \\
\text { (years) }\end{array}$ & $\begin{array}{l}\text { Stage of } \\
\text { training } \\
\text { (weeks) }\end{array}$ & Site & Radiograph & $\begin{array}{c}\text { Bone } \\
\text { scan }\end{array}$ & $\begin{array}{c}\text { Date } \\
\text { presented }\end{array}$ & $\begin{array}{c}\text { Date } \\
\text { diagnosed }\end{array}$ & $\begin{array}{c}\text { Delay in } \\
\text { diagnosis } \\
\text { (days) }\end{array}$ & $\begin{array}{l}\text { Outcome } \\
\text { (see text) }\end{array}$ \\
\hline 1 & 19 & 24 & R FEM & - & + & 29/04/90 & $31 / 05 / 90$ & 32 & Passed out \\
\hline 2 & 22 & 24 & LNOF & - & + & $26 / 04 / 90$ & $09 / 05 / 90$ & 13 & Hunter \\
\hline 3 & 20 & 9 & RNOF & + & + & $28 / 08 / 90$ & $16 / 10 / 90$ & 49 & Hunter \\
\hline 4 & 19 & 1 & LNOF & + & + & $31 / 05 / 90$ & $05 / 07 / 90$ & 35 & In training \\
\hline 5 & 18 & 22 & R FEM & + & NA & $19 / 07 / 89$ & $28 / 07 / 89$ & 9 & Passed out \\
\hline 6 & 19 & 7 & R FEM & + & + & 17/11/90 & $26 / 11 / 90$ & 9 & Hunter \\
\hline 7 & 21 & 27 & L FEM & - & + & $17 / 12 / 90$ & $08 / 01 / 91$ & 22 & Hunter \\
\hline 8 & 19 & 24 & RNOF & + & + & $12 / 12 / 90$ & 08/01/91 & 27 & Hunter \\
\hline 9 & 23 & 22 & L\&R FEM & + & + & $16 / 10 / 89$ & $22 / 11 / 89$ & 36 & Passed out \\
\hline 10 & 17 & 24 & RNOF & - & + & $07 / 01 / 91$ & $29 / 01 / 91$ & 22 & Hunter \\
\hline Mean & 19.7 & & & & & & & 25.4 & \\
\hline
\end{tabular}

FEM, femoral shaft; NOF, neck of femur 


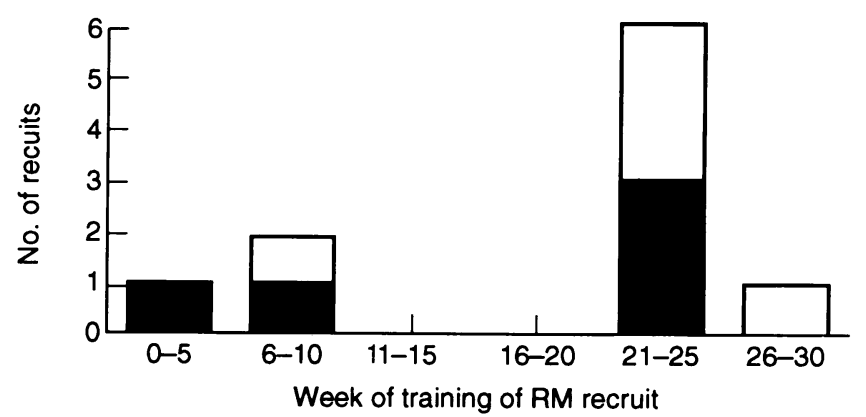

Figure 3. Stress fractures of the hip analysed by week of training. $\square$, Fracture of neck of femur; $\square$, fracture of upper femoral shaft

demonstrated such high rates of stress fracture of the hip. Gill and Hopkins ${ }^{7}$ looked at stress fractures in parachute regiment recruits, and found only two femoral fractures out of a total of $44(4 \%)$ in 1 year. Morgan ${ }^{4}$ studied the radiographs taken at CTCRM between 1985 and 1987, and found radiographic evidence of 179 stress fractures; however, only one of these was femoral. A study of sports-related injuries at the Belfast City Hospital in 1983 identified 35 stress fractures out of 1277 injuries presented; however, none of these were femoral stress fractures. ${ }^{8}$. The only prospective studies on stress fractures have demonstrated much higher incidences of hip fractures ${ }^{6,9}$.

There were no apparent differences between the presentation of the two types of stress fracture reported here, and there was no difference in the type of fracture seen at the various stages of training. Fractures of the femoral shaft have been reported as being more common than those of the femoral neck in previous studies and reports ${ }^{6,10}$. One important factor here may be that femoral stress fractures have a tendency to be asymptomatic. The study by Milgrom et al. $^{6}$ on Israeli military recruits showed that $69 \%$ of femoral stress fractures were asymptomatic, and were only found on the bone scans. Our data support this: several of the bone scans had evidence of more than one area of increased uptake of the radionuclide in the femoral shaft, when the patient had pain at only one site. The dangers of this are obvious. A relatively asymptomatic patient may develop a complete fracture at a site of previous stress fracture. Luchini et al. cite the example of two marathon runners who did just this ${ }^{11}$.

One of our patients (Case 5) presented acutely with a catastrophic failure of the stress fracture whilst on the assault course. He had had 1 week's history of an ache in his right thigh, and had been treated with rest and non-steroidal anti-inflammatory drugs, but continued with his troop. At the time of injury, he was on an assault course, crawling along a rope. There was no history of trauma. He collapsed in great pain, and was unable to bear weight on that limb. Radiographs demonstrated a displaced spiral fracture of the upper third of the right femur. He was treated with intramedullary nail fixation, made a good recovery, and eventually passed out of training 18 months after the injury.
The occurrence of multiple stress fractures in a subject is also interesting. Blatz described a 15 -yearold female track runner with bilateral femoral and tibial shaft stress fractures ${ }^{1,2}$. One of our patients (Case 9) had these same four fractures evident on bone scanning (Figure 4), but recovered after a period of absolute rest. He returned to training and eventually completed training. He later attended another strenuous course at CTCRM, during which he developed a metatarsal stress fracture. Thus, this one patient had developed five separate stress fractures.

The analysis of stress fractures by week of training reveals that stress fractures were more common in the last few weeks of training. This is presumably related to increases in both the distances covered, and the weight carried, by the recruits during these last few weeks. Several other studies have shown a higher incidence of stress fractures in the first few weeks of training ${ }^{6,9}$. This change may be related to alterations in the training programme of Royal Marine recruits over the last few years: for example, improved footwear, a resprung gymnasium floor and the wearing of shock attenuating insoles. There was no difference in the site of the stress fractures found at the various weeks of training.

The mean delay in diagnosis of these femoral stress fractures was 25.4 days. A reduction in this interval is

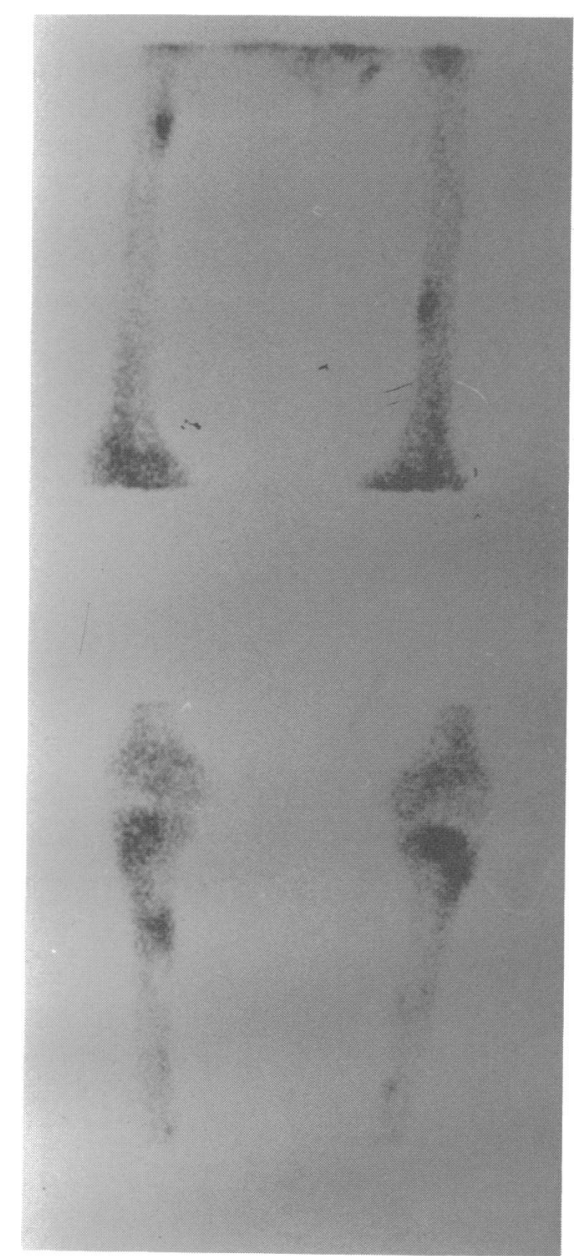

Figure 4. ${ }^{99 m} \mathrm{Tc}$-scintigram showing increased uptake in both femora and both tibiae 
obviously desirable. Most of these patients presented with a 'groin strain', or 'pulled thigh muscle', which may be misleading. Some of the patients appear to have markedly higher pain thresholds than others, and may not return for investigation after initial consultation.

A further factor in delay in presentation is that four out of the ten stress fractures had normal radiographs taken of the abnormal side, even when the radiographs were scrutinized in retrospect. This has important implications: a normal radiograph does not exclude a stress fracture. Bone scintigraphy must be performed in all cases where the diagnosis is in doubt.

In conclusion, stress fractures of the femur may be more common than previously identified. Early diagnosis is important to avoid the catastrophic failure of the stress fracture seen in one of our subjects. A heightened awareness of the occurrence of these injuries, combined with improved and earlier investigation - in particular bone scintigraphy - may lead to earlier diagnosis.

\section{Acknowledgements}

The authors wish to thank the Physics department of the Royal Devon and Exeter Hospital, Wonford, who performed the bone scintigraphy on all patients. We also wish to thank the Royal Navy for permission to publish this report.

\section{References}

1 Breithaupt MD. Zur pathologie Des Mensch Lichen Fusses. Med Zeitung 1855; 24: 169-71, 175-7.

2 Stechow AW. Fussoedem und Roentgenstrahlen. Dtsch Mil-aertzl Zeitg 1897; 26: 465-71.

3 Fullerton LR. Femoral neck stress fractures. Sports Med 1990; 9(3): 192-7.

4 Morgan NV. Stress fractures in Royal Marine Recruits 1985-1987. Thesis for Diploma in Sports Medicine 1988.

5 Brubaker CE, James SL. Injuries to runners. J Sports Med 1974; 2(2): 189-98.

6 Milgrom C, Giladi M, Stein M et al. Stress fractures in military recruits. J Bone Joint Surg [Br] 1985; 67-B: 732-5.

7 Gill RMF, Hopkins GO. Stress fracture in Parachute Regiment recruits. J R Army Med Corps 1988; 134: 91-3.

8 Dowey KE, Moore GW. Stress fractures in athletes. Ulster Med $J$ 1984; 53(2): 121-4.

9 Greaney B, Gerber FH, Laughlin RL et al. Distribution and natural history of stress fractures in U.S. Marine recruits. Radiology 1983; 146: 339-46.

10 McBryde AM Jr. Stress fractures in athletes. Sports Med 1975; 3(5): 212-17.

11 Luchini MA, Sarokhan AJ, Micheli LJ. Acute displaced femoral shaft fractures in long-distance runners: two case reports. J Bone Joint Surg [Am] 1983; 65-A: 689-91.

12 Blatz DJ. Bilateral femoral and tibial shaft stress fractures in a runner. Am J Sports Med 1981; 9(5): 322-5. 
competitors. Such power event competitors may demonstrate up to $95 \%$ FT fibres which are metabolically equipped for forceful contractions that depend largely on anaerobic mechanisms for energy supply. FT fibres may also be two to four times faster and approximately $50 \%$ larger than fibres classified as slow. It should be noted here that the athlete's muscle fibre profile is determined both by genetic and environmental (training) factors ${ }^{3}$. No obvious muscle fibre profile differences have been established between men and women competing in similar events.

While muscle size has been associated with muscular strength, hypertrophy (the increase in muscle size or bulk) has been associated with gains in strength. However, because muscular development is partly linked with plasma testosterone levels, men are capable of considerably greater gains in muscle bulk than are women. Some researchers have concluded that muscular hypertrophy in women is not a necessary consequence of strength training.

\section{Conclusion}

Ward and Whipp ${ }^{4}$ plotted the decade-by-decade improvement in the mean running velocity for both men and women for all events between $200 \mathrm{~m}$ and the marathon. It was found that the improvement rate for women is more than double that for men, reflecting both the increased numbers of women coming into sport and the proportionately greater increases in their training.

\section{References ,}

1 Koutedakis Y, Sharp NCC. A modified Wingate test for measuring anaerobic work of the upper body in junior rowers. Br J Sports Med 1986; 20: 153-6.

2 Davies CTM. Strength and mechanical properties of muscle in children and young adults. Scand J Sports Sci 1985; 7: 11-15.

3 Komi PV. The musculoskeletal system. In: Dirix A, Knuttgen HG, Tittel K, eds. The Olympic Book of Sports Medicine. Oxford: Blackwell Scientific Publishers, 1988: 15-39.

4 Ward SA, Whipp BJ. Will women outperform men in Olympic running in the twenty-first century? I Physiol 1990; 423: 24P.

\section{Errata}

Stoneham MD, Morgan NV. Stress fractures of the hip in Royal Marine recruits under training: a retrospective analysis. Br J Sports Med 1991; 25: 145-8.

The publishers wish to apologise for the accidental substitution of an incorrect address for correspondence.

Please send correspondence to:

Surgeon Commander N. V. Morgan RN, Brigade Medical Adviser, 3 Commando Brigade, Stonehouse Barracks, Plymouth, UK.
McCaw ST, Bates BT. Biomechanical implications of mild leg length inequality. Br J Sports Med 1991; 25: 10-13.

The publishers also wish to apologise for the incorrect spelling of Dr S. T. McCaw's name both in the table of contents and the article running head. 